\title{
University Bridge Program: Innovation at the grass roots of learning in higher education.
}

\author{
RajaniKanth Aluvalu \\ Department of Computer Engineering School of Engineering, \\ RK University, Rajkot, Gujarat, India \\ rajnikanth.aluvalu@rku.ac.in
}

\begin{abstract}
In India universities and colleges typically assume that students entering their first year of higher education are sufficiently prepared to be successful in college level studies. However, many studies have conclusively shown that most students perform at significantly lower grade level during graduate courses compared to their actual grade in 12th standard. Students from various geographical locations, boards of study, economical back grounds and medium of study will take admission to university courses. Faculty teaching university courses will experience heterogeneous student groups in terms of proficiency in pre-requistes for university courses. We had designed a unique program at RK University (RKU) to overcome the above challenges, which is discussed in this paper. This program has achieved great success in improving students learning in university undergraduate and post graduate courses to get head start on their academic goals. In this paper, we will explore the design and implementation of University Bridge Program (UBP) at RKU.
\end{abstract}

Keywords: Higher education, Educational equity, globalization, active learning.

\footnotetext{
RajaniKanth Aluvalu, Department of Computer Engineering School of Engineering, RK University, Rajkot, Gujarat, India rajnikanth.aluvalu@rku.ac.in
}

\section{Introduction:}

Indian Higher education system, like in many other countries is under pressure from various directions to improve its performance [3]. Faculties teaching courses at university level are not satisfied with the prerequisite knowledge, skills and learning behaviour of entry level students. Faculties believe that "most" of the students they teach lack the basic skills for university-level courses. Usually students taken admission in university courses come from various learning environments and even their medium of education is different, particularly in India where we have many regional languages. Many students do not have an understanding on domains and courses of study [3]. Knowing domain applications is very much important as courses offered at university level are professional, which leads to employment. Indian Higher education system is facing severe competition on account of globalization and preparing world competent graduates [3].The educational priorities started changing due to the changes in the relative influence of stake holder groups and new forces like globalization [10]. To overcome the above challenges students require broad understanding on fundamentals with critical thinking skills. At the end of graduation students are required to acquire the below graduate attributes to become globally competitive.
A. Graduate attributes [12] :
- Good understanding on domain fundamentals. 
Multi disciplinary, systems perspective.

Basic understanding of the context like economics, environment, society.

- Good communication skills in terms of written, oral, graphic and listening.

- Ability to think critically and creatively-both independently and cooperatively.

Curiosity to learn in life.

Understanding on importance of team work.

As mentioned, teaching graduate/post graduate course to these heterogeneous student groups is a challenge to faculties many students fail in catching the context of the course, because of lack of fundamental understanding of domain they are studying and skills required for graduate program at University. There is a need of conducting a prerequisite course for all the fresh entry students to university courses for basic skills preparation.

\section{University Bridge Program:}

We at RK University have consistently observed significantly low college-readiness among students which seems to be a nationwide systemic issue [11]. Being a new age university we had to find a way to come out of this problem. "The problem is twofold for RKU in particular. On one front we have to make sure that students have necessary domain knowledge to successfully grasp concepts beyond their previous grade level. On the other front, we need to ensure that students are ready to study in an environment that is polar opposite of they would have experienced in school. RKU is moving towards outcome based education with active learning teaching and learning methods throughout all courses and programs. Our pedagogy emphasises self learning, group work and participation" [8][13]. Most classes are activity based requiring team work and self guided work. Active class participation is necessary for success at RKU. These active learning methods are a standard in all top universities across the globe but are a rarity in India [1][4][6]. We are spearheading this approach to teaching and learning at RKU. But it would be unwise to expect the students, who are habituated to passive learning modes for a decade during their schooling to start participating and thriving in active learning approach without any programmatic intervention. This is where UBP comes into picture. The UBP expertly blends basic pre- requisite skills and understanding on domain required for successful transition into university courses [5].

The primary objectives of UBP are:

- To get students ready to learn in a new environment.

- To encourage self learning.

- To bridge knowledge gaps in core areas.

- To bridge communication skills gap.

- To promote group learning and team work.

- To get familiar with active learning.

\section{UBP design and Curriculum offered:}

Every academic year for fresh admits, we begin with student orientation program scheduled for couple of days. We had identified orientation program with a stretch of 2-3 days is simply not enough time to get to the depth we needed nor to even begin to scratch the surface of the paradigm shift in learning approach we envisioned. If we were going to intervene, then it had to be a full throttle approach. After considerable brainstorming we finalized a program of 3 to 4 weeks with 5 areas of focus common to all schools and one or two areas specific to each school's need. For eg. School of Engineering has a four week UBP. The common thread running through all modules is that they are designed to be highly active and participatory involving extensive group work and self exploration. We had planned UBP as a comprehensive interventional program for all the first year students across all schools of RKU. Students undergo UBP immediately at the beginning upon taking admission in University [13]. Designing and implementing UBP has been no small task. It involved months of course planning and managing huge logistical challenges in implementation. Once we were clear on the goals of this program, we began to identify the courses and design the course content and its implementation. For designing the course content, we started identifying faculty across university familiar and proficient with the courses finalized for UBP. Identified faculty pool finalized syllabus for their respective courses. University academic board had valuated and approved the syllabus designed [13].

\section{A. Common courses include:}

- Life skills focusing on creative thinking, critical thinking, and emotion control etc.

- Soft Skills focusing on communication skills, relationship skills, etc. 
Personality Development focusing on developing a "contributor" personality.

- Information Literacy for 21 st Century focusing on Google Apps (deployed at RKU), LMS (Edmodo), office applications, etc.

- Yes+Happiness (Art of living course) focusing on meditation, ethics, stress relief and sudharshan kriya etc.

\section{B. School specific courses include:}

Refresher course on physics and mathematics focusing on fundamentals of physics and mathematics with their applications.

Introduction to engineering focusing on understanding of all core branches of engineering. Offered to all Engineering students.

- Introduction to pharmacy focusing on basics of pharmacy helps as pre requiste for B.Pharm students.

- Professional orientation of physiotherapy focusing on basics of physiotherapy helps as prerequisite for B.Pt students

\section{Training faculties on active learning methods:}

"Active learning", in short, anything students do in class related to learning other than passively listening to an instructor's lecture [1]. In active learning model faculty divides the whole session into segments and usually each not more than 20 minutes and teaches for short time and then gives time to the students for discussion/activity. Active learning helps students develop cognitive and higher-order thinking skills. The UBP course work is planned to be delivered using active learning techniques.

The faculties at RKU were trained on active learning techniques by Mr. Mohit Patel through a short term training program Learning Experience Design (LED) [4][2]. Mr. Patel pursued his MS in education from Harvard University, USA. UBP courses are allocated only to the faculties' undergone LED program training.

Faculties had prepared micro lesson plans for each session. Each lesson plan includes learning objectives, assessment and set of activities to be carried out with specific time. All the lesson plans prepared by faculty will go through peer review process. The entire faculty team teaching particular course of program has to follow the same lesson plan. Lesson plans helped us in achieving uniformity in course delivery across multiple classes in university by different faculty.

\section{UBP Implementation:}

We had started offering exhaustive university bridge program (UBP) from the academic year 201415.Students taken admission from the said academic year had started experiencing UBP that no other student has experienced at RKU before [13]. The University Bridge Program (UBP) is so unique and comprehensive that students and teachers both have been surprised by the engagement that new students have felt during this program [6].

After detailed planning, the big issue that we had to confront was the logistical challenge of delivering the program effectively. Planning involved the correct mapping of faculties with modules, managing extremely divergent time tables coupled with different commencement dates of different programs, managing existing faculty load of higher semesters, and coping with ever changing admission schedules. Truly, the implementation is an operational masterpiece. Without the incredible efforts of all faculties involved in planning and execution, UBP would not have been in existence.

\section{Result analysis:}

We had taken feedback from students after completing UBP. The student response has been unanimously positive. We are ecstatic by the feedback. Students felt 'weightless', without any burden, when they are involved in activities. The feedback responses indicated us that we are on the right path. We had analysed the academic results of these students in further semesters and found overall improvement in student performance.UBP helped the students in successful transition into the admitted university courses.

We had taken feedback on various parameters. Figure-1 shows feedback given by students on UBP course content and organization, $96 \%$ of the students are satisfied with course content and organization. 


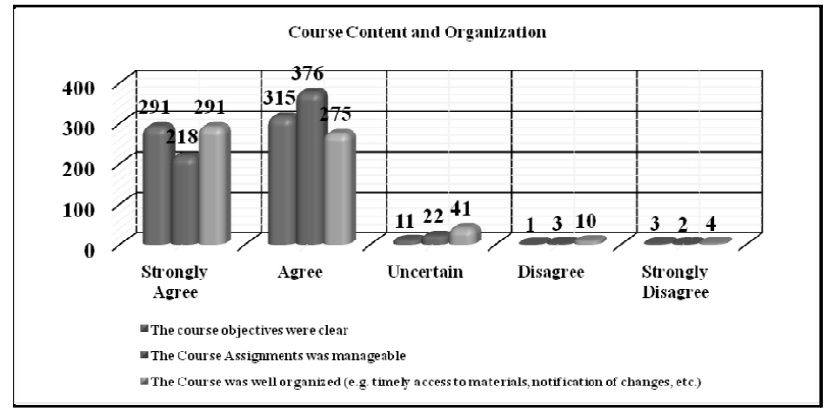

Figure - 1

Below figure-2 shows students attendance in UBP. Active teaching methods in UBP and course content motivated the students to attend the lecture regularly and $80 \%$ of the students had attended more than $80 \%$ of the lectures.

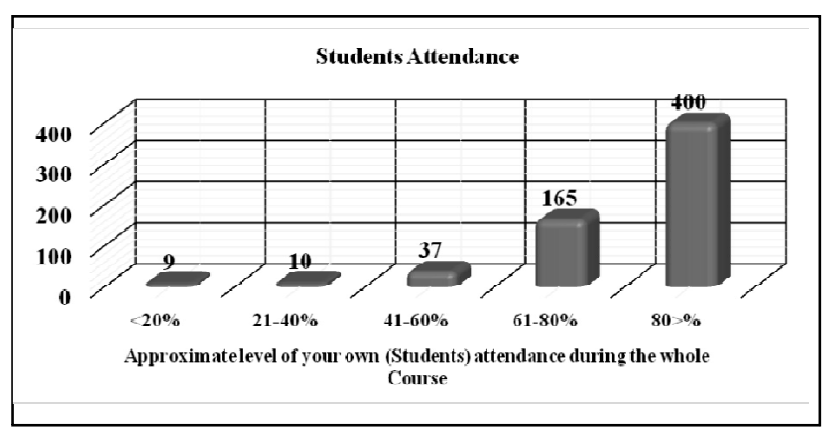

Figure - 2.

As the complete UBP delivery is based on active learning strategies we had taken feedback on students' contribution and participation in class activities such as roleplays, discussions, quiz, comprehensive writing etc. Figure- 3 shows the responses, $98 \%$ of the students had actively participated in the activities planned by faculties in sessions.

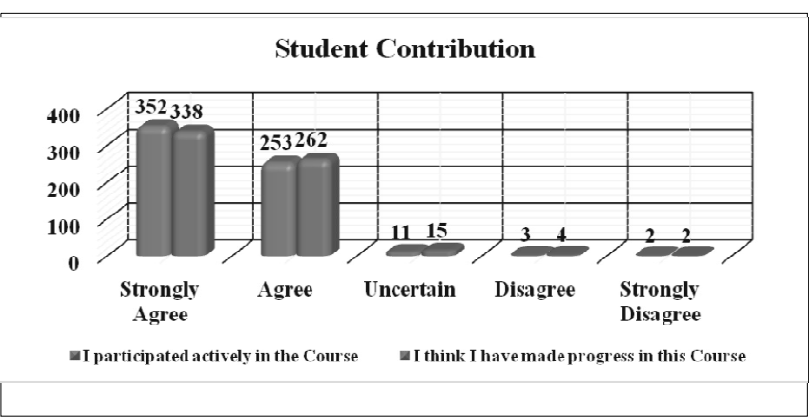

Figure-3.

We had also surveyed student satisfaction on learning environment and teaching methods. Figure-4 shows the responses given by students. $97 \%$ of the students had expressed their satisfaction with the learning environment and active teaching methods followed by faculties for conducting sessions. Students mentioned that activities helped them in learning the fundementals easily.

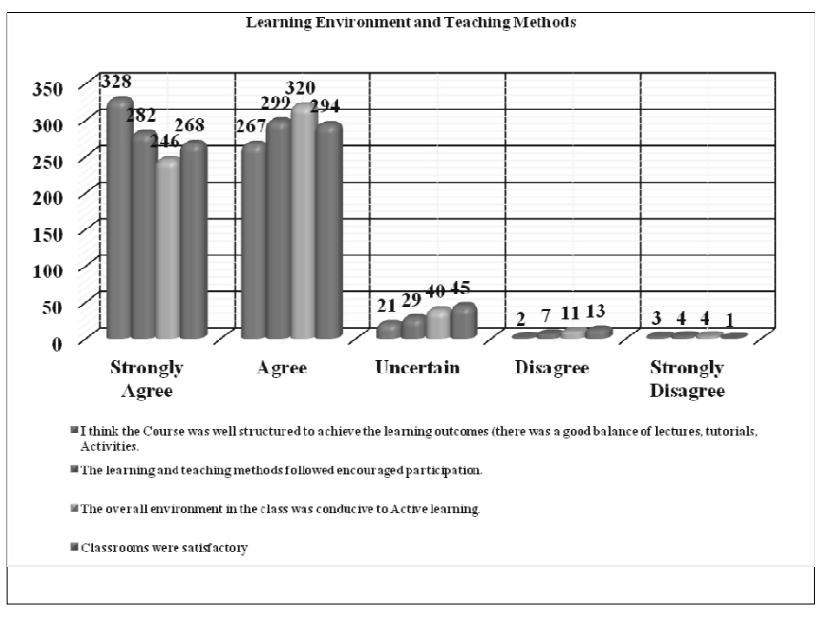

Figure -4

We had evaluated performance of UBP instructors and the feedback responses are very positive. Figure- 5 shows the responses on instructor evaluation. $97 \%$ of the students are satisfied with the faculties.

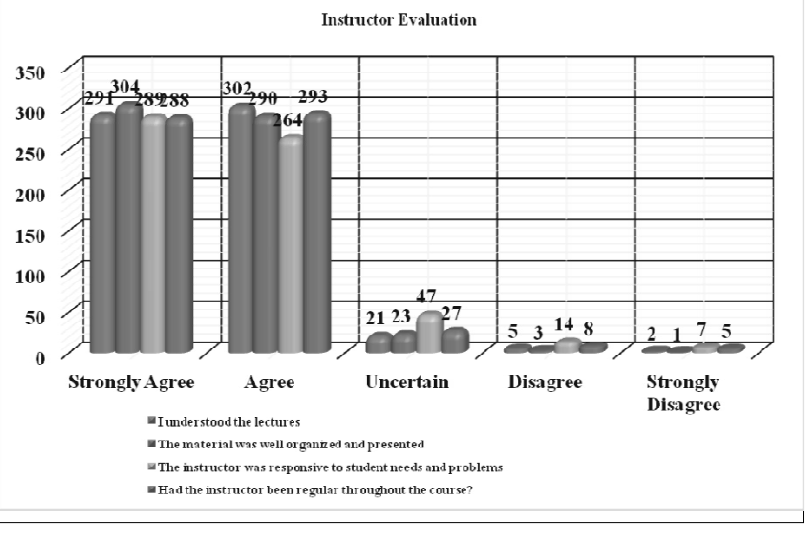

Figure-5

\section{Conclusion:}

UBP is one of the many systemic grassroots innovations that RKU is spearheading. Students at RKU started experiencing active learning. Now our faculty during their regular courses experiencing participatory class from the UBP students. Only a teacher can tell you how hard it is to make classes truly enjoyable. Every year we will make necessary 
modifications to UBP course structure based on the feedback received from students and Faculty. We have taken on this challenge and if UBP feedback is an indication, then we are on the right track, doing the right thing.UBP can be Implemented in various Higher education institutions in India.

\section{Acknowledgement}

I would like to thank all the people who contributed to the work described in this paper. I am also indebted to Mr. Mohitpatel, who deserves the credit for initiating, designing UBP at RK University. Every result described in this paper was accomplished with the help and support of management of RK University and UBP core Team.

\section{References}

[1]. Bonwell, C.C, and J. A. Eison. 1991. Active Learning: Creating Excitement in the Classroom. (ASHE-ERIC Higher Education Report No. 1, 1991) Washington, D.C.: George Washington University Clearinghouse on Higher Education.

[2]. Mohit Patel (2014). Learning experience design, www.blog.rku.ac.in.

[3]. Sanatkaul (May, 2006), Higher Education in India: seizing the opportunity.ICRIER, New Delhi.

[4]. Meyers, C. and T. Jones. 1993. Promoting Active
Learning: Strategies for the College Classroom. San Francisco: Jossey-Bass.

[5].Goodsell, A.Maher and V.Tinto.1992. Collaborative Learning: A Sourcebook for Higher Education. University Park: The National Centre on Postsecondary Teaching, Learning, and Assessment.

[6]. Davis, T. M. and Murrell, P. H. 1993.Turning Teaching into Learning: The Role of Student Responsibility in the Collegiate Experience, ASHE-ERIC Higher Education Research Report, No. 1, Washington, D.C.

[7]. De Corte, E., (2003), Excellence in Higher Education, Portland Press, London.

[8]. Elton, L., (1998), Dimensions of excellence in university teaching, International Journal for Academic Development, vol. 3, no 1

[9]. Michael Prince (2004). Does Active Learning Work? A review of the Research. J.Engr. Education, 93(3), 223-231.

[10]. Martin carnoy, Rafiq Dossani (2012), Goals and governance of higher education in India, Springer science.

[11]. www.rku.ac.in.

[12].www.nbaind.org/Files/UG_Tier_II\%20Manual.pdf

[13].http://blog.rku.ac.in/post/94236397895/universi ty-bridge-program-innovation-at-the 